\title{
Antimicrobial Effect and Antioxidant Activity of Triterpenes Isolated from Gymnema sylvestre $\mathrm{R}$. Br.
}

\author{
Valeria Romanucci $\odot^{* 1}$, Maria Giordano $\odot^{2}$, Sergio Davinelli ${ }^{3}{ }^{3}$, \\ Cinzia Di Marino ${ }^{1}$, Afef Ladhari ${ }^{4}{ }^{4}$ and Anna De Marco 5
}

\author{
${ }^{1}$ Department of Chemical Sciences, University Federico II, Via Cinthia 4, 80126 Napoli, Italy \\ ${ }^{2}$ Department of Agricultural Sciences, University Federico II, 80055 Portici, Italy \\ ${ }^{3}$ Department of Epidemiology, Harvard T.H. Chan School of Public Health, Boston, MA 02115, \\ United States \\ ${ }^{4}$ Université de Carthage, Institut National Agronomique de Tunisie (INAT), Laboratoire GREEN- \\ TEAM (LR17AGR01), 43 avenue Charles Nicolle, 1082 Tunis, Tunisie \\ ${ }^{5}$ Department of Pharmacy, University Federico II, Via Montesano 49, 80131 Napoli, Italy
}

(Received October 14, 2019; Revised December 12, 2019; Accepted December 20, 2019)

\begin{abstract}
Gymnema sylvestre is a commonly used herb in Ayurvedic medicine. The demand for its extracts in the commercial and pharmaceutical fields has been steadily increasing in recent years. Its extracts are used to treat various ailments as well as for their antimicrobial properties. This study has evaluated the antimicrobial effects of different $G$. sylvestre extracts and of eight triterpenes isolated from the most active extract on six bacterial poultry pathogens i.e. Bacillus subtilis, Enterococcus faecalis, Staphylococcus aureus, Pseudomonas aeruginosa, Escherichia coli and Enterobacter aerogenes. In particular, it has been evaluated the minimum inhibitory concentration (MIC) and minimal bactericidal concentration (MBC) of all extracts and isolated triterpenes. Finally, the cytotoxicity activity of triterpenes was evaluated by MTT assay and their antioxidant activity in basal and oxidant conditions by DCFH-DA assay.
\end{abstract}

Keywords: Gymnema sylvestre; antimicrobial effects; triterpenes; gymnemic acids; herbal drug; DCFH-DA assay. (C2020 ACG Publication. All right reserved.

\section{Plant Source}

Gymnema sylvestre $\mathrm{R}$. Br. is a large climbing plant belonging to the Asclepiadaceae family, widespread in the tropical areas of Asia, Africa and Australia. The plant presents branches covered with petiolate leaves, with an oval shape, elliptical powder and with a characteristic bitterish and acrid taste. The flowers are typically campanulate and gathered in pedunculated racemes. G. sylvestre was mentioned for the first time in the European scientific literature in 1847 by Edgeworth and, successively, by Hooper [1], but its properties were already known in Indian medicine. More in details, it is known that the inhabitants of Bombay and Gujarat are used to chew fresh leaves of $G$. sylvestre to reduce glycosuria. Both leaves and dried roots of the plant are used in Ayurvedic medicine [2]. Plants are real reservoirs of secondary metabolites belonging to different classes of substances [3-

${ }^{*}$ Corresponding author: E-Mail: valeria.romanucci@unina.it 
5], some structurally very complex [6-8]. The interest in the isolation and structural determination of natural compounds is strictly in relation to their possible use as herbicides [9-10], algaecides [11-13], insecticides or drugs [14]. The present study was designed to evaluate the antibacterial activity of several extracts of $G$. sylvestre leaves and eight triterpenes isolated from the most active extract. Finally, an in vitro cell growth was achieved by $50 \%$ and the ability to exert antioxidant activity.

\section{Previous Studies}

The eight triterpenes (1-8) reported in Figure 1 have been isolated from the most active extract of G. sylvestre leaves [15] The dried and powdered leaves of $G$. sylvestre were sequentially extracted with water $\left(\mathrm{H}_{2} \mathrm{O}\right)$ and methylene chloride $(\mathrm{DCM})$. The organic fraction contained the much of phenolic compounds and the highest antioxidant activity [16]. The ethyl acetate (AcOEt) fraction was chromatographed on silica gel and the fractions obtained were purified by HPLC to give a new lupanetype triterpene (1) and seven oleane-type triterpenes (2-8) (Figure 1).

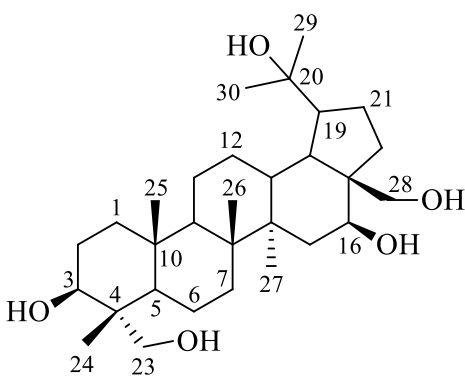

1

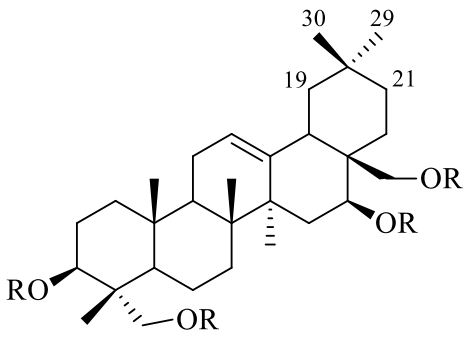

$2 \mathrm{R}=\mathrm{H}$

$3 \mathrm{R}=\mathrm{CH}_{3} \mathrm{CO}$

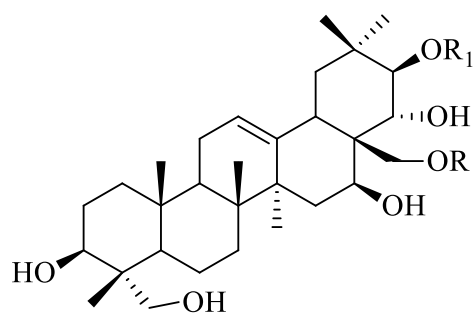

$4 \mathrm{R}=\mathrm{CH}_{3} \mathrm{CO} \quad \mathrm{R}_{1}=\mathbf{M b a}$

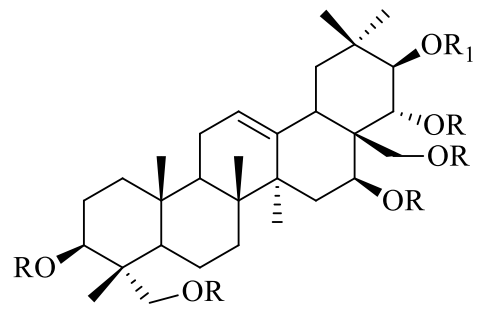

$5 \mathrm{R}=\mathrm{R}_{1}=\mathrm{H}$

$6 \mathrm{R}=\mathrm{H} \quad \mathrm{R}_{1}=\mathbf{M b a}$

$7 \mathrm{R}=\mathrm{CH}_{3} \mathrm{CO} \quad \mathrm{R}_{1}=\mathbf{M b a}$

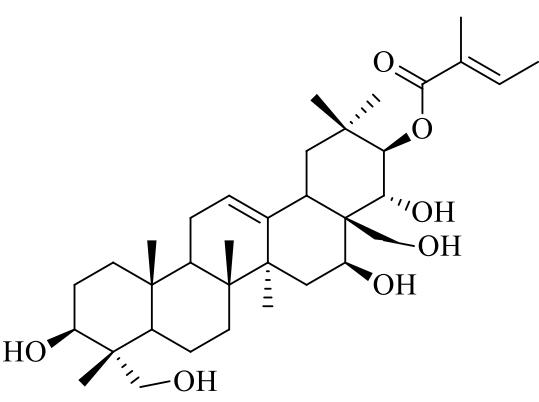<smiles>CCC(C)C(C)=O</smiles>

Mba $=2 S$-Methylbutanoil

Figure 1. Structures of the lupane (1) and oleane-type triterpenes (2-8).

\section{Present Study}

Today it is known that plants are a precious reservoir of secondary metabolites with low molecular weight [17-19], belonging to numerous classes of substances [3-5] and used for the defense against insects, microorganisms or even from other plants [9-13]. Over the years, there was a continuous and ever increasing request of new natural substances that are commonly considered nontoxic and safer than synthetic ones [20-21]. Considering that one of the most serious health threats is the antimicrobial resistance (AMR) [22], recently, there was an increasing interest in natural extracts or their single components endowed with antimicrobial activity. This work is a part of a more general 
project that aims to define new uses for natural extracts or for their individual components. The antibacterial activity of several extracts of G. sylvestre leaves and eight triterpenes isolated from the most active extract has been evaluated. The six bacterial poultry pathogens tested by a microtiter dilution assay are: Bacillus subtilis, Enterococcus faecalis, Staphylococcus aureus, Pseudomonas aeruginosa, Escherichia coli and Enterobacter aerogenes. [23].

Plant Material: G. sylvestre was purchased from Mother Herbs Ltd., 13 Street, Madhu Vihar, Patpadganj, Delhi - 110 092, India, E-mail: info@motherherbs.com and identified by Prof. Gabriele Pinto of the Dipartimento di Scienze Biologiche of the University of Naples. A sample specimen (HERBAZLS 317a) has been deposited at the herbarium of the University Federico II.

Thus, G. sylvestre leaves were infused first with water and then with DCM. The organic phase, reduced in volume, was debated with an aqueous solution of $2 \mathrm{~N}$ of $\mathrm{NaOH}$ and the neutral phase was reduced in volume and neutralized. The latter fraction was finally chromatographed on silica gel eluting with petroleum ether (PE), dichloromethane (DCM), ethyl acetate (EA), acetone (A), methanol (M) and water (W) (Figure S1) Each fraction was tested on three strains of Gram-positive bacteria such as B. subtilis, E. faecalis, S. aureus, and three Gram-negative ones such as P. aeruginosa, E. coli and E. aerogenes. Table S1 shows the minimum inhibitory concentration (MIC) for each microorganism, while in Table $\mathrm{S} 2$ it is reported the minimum bactericidal concentration (MBC).

The values of minimum inhibitory concentrations (MIC) vary between $168.3 \mathrm{mg} / \mathrm{L}$ of the PE extract on E. faecalis and the $75.4 \mathrm{mg} / \mathrm{L}$ of the EA extract on B. subtilis. The most active extract was that obtained with EA with MIC values not higher than $91.3 \mathrm{mg} / \mathrm{L}$ on E. aerogenes, while the less active was the least polar ones with MIC values always higher than $140 \mathrm{mg} / \mathrm{L}$. Intermediate values for the other extracts were reported, in particular that obtained by DCM seems the most active. Table S2 confirms that regardless of the organism considered, the extract with EA is the most interesting with a total inhibition of microbial growth around 156.2 and $201.3 \mathrm{mg} / \mathrm{L}$ that in some cases are just above those of the control. However, MIC, MBC values also indicated that the species more sensitive to the action of the most active extract are E. faecalis and E. coli.

The isolated triterpenes (Figure 1) have been assayed on the same bacteria strains, evaluating for each microorganism both the minimum inhibitory concentration (MIC, Table S3) and the minimum bactericidal concentration (MBC, Table S4).

The MIC values vary between $21.8 \mathrm{mg} / \mathrm{L}$ of triterpene 1 on $B$. subtilis and the $7.2 \mathrm{mg} / \mathrm{L}$ of triterpenes $\mathbf{3}$ and $\mathbf{7}$ on $B$. subtilis and E. coli, respectively. In general, the most active ones are the triterpenes $3, \mathbf{4}$ and 7, with an oleane skeleton, full acetylated to hydroxyl groups or in part acetylated and esterified with a $2 \mathrm{~S}$-methylbutanoic acid unit instead resulted less active the polar triterpenes $\mathbf{2}, \mathbf{5}$ and 6. In particular, the triterpene $\mathbf{2}$ corresponds to the triterpene $\mathbf{3}$ with hydroxyl groups not acetylated, while the triterpenes $\mathbf{5}$ and $\mathbf{6}$ are similar to the triterpene $\mathbf{7}$ with all hydroxyl functions free. the triterpene $\mathbf{6}$ is also esterified with the 2S-methylbutanoic acid to the hydroxyl group at C-21 carbon (see supporting information for detail)

Regarding the MBC values reported in the Table S4, the triterpenes 3, 4 and 7 completely inhibit microbial growth at values of concentrations between 17.1 and $21.6 \mathrm{mg} / \mathrm{L}$. As for the extracts data, MIC and MBC values also indicate that the species more sensitive are B. subtilis and E. coli.

For an initial characterisation of biological properties of isolated compounds and in view of their potential clinical use, we initially utilised an in vitro cell model to calculate the concentration inhibiting cell growth by $50 \%\left(\mathrm{IC}_{50}\right)$ and also to evaluate if they exert any antioxidant activity. Rat diploid immortalised fibroblasts represent one of the simplest available and widely used cellular models for toxicological assays. In addition considering that rat and human cells generally exhibit good metabolic similarity, results obtained on rat cells are typically confirmed in humans.

Cytotoxicity assays were performed using the MTT test, as previously described [17]. Exponentially growing cultures of rat fibroblasts were exposed to increasing concentrations of each compound $(0-1 \mathrm{mM})$ and cell viability was assessed after $48 \mathrm{~h}$. A dose-dependent decrease in viable cells was observed with all tested compounds with an $\mathrm{IC}_{50}$ ranging between 28 and $839 \mu \mathrm{M}$ (Table S5). 
To assess the potential antioxidant activity of the compounds, we decided to use a dose of 30 $\mu \mathrm{M}$ for all compounds since the majority of them did not exert an evident toxic effect at such dose. Intracellular reactive oxygen species (ROS) levels were measured by the oxidative conversion of stable, non-fluorescent $2^{`}, 7^{`}$-dichlorofluorescein diacetate (DCFH-DA) to the highly fluorescent $2^{`}, 7$-dichlorofluorescein (DCF) occurring in the presence of ROS.

The DCFH-DA test was preferred over the traditional in vitro assays because it takes into account the solubility and the cellular uptake of tested compounds, which are important variables when assessing their potential use in humans. Moreover, the test discriminates the different types of ROS, such as superoxide radical, hydroxyl radical, and hydrogen peroxide, which are all relevant in an in vivo setting. Therefore, the fluorescence detected is a sensitive indicator of intracellular ROS. We evaluated the effect of ROS exposure to compounds for variable times (1,16 and $48 \mathrm{~h}$ ) on the basal intracellular ROS level and on oxidative conditions induced by $\mathrm{H}_{2} \mathrm{O}_{2}$.

As shown in Figure 2, we did not detect any significant effect on basal and oxidative conditions; in details most of compounds (i.e, compounds $2, \mathbf{3}, \mathbf{5}$ and $\mathbf{6}$ ) induced an increase, in the basal level of ROS. Compounds 4 and 7 showed a slight antioxidant activity. After $16 \mathrm{~h}$, the less active compounds appeared to further increase their activity, also the compounds $\mathbf{4}$ and $\mathbf{7}$ have more or less the same value of control. After $48 \mathrm{~h}$, all compounds displayed activity below the threshold value of the control sample, with the exception of the less active compounds $\mathbf{2}$ and $\mathbf{3}$.
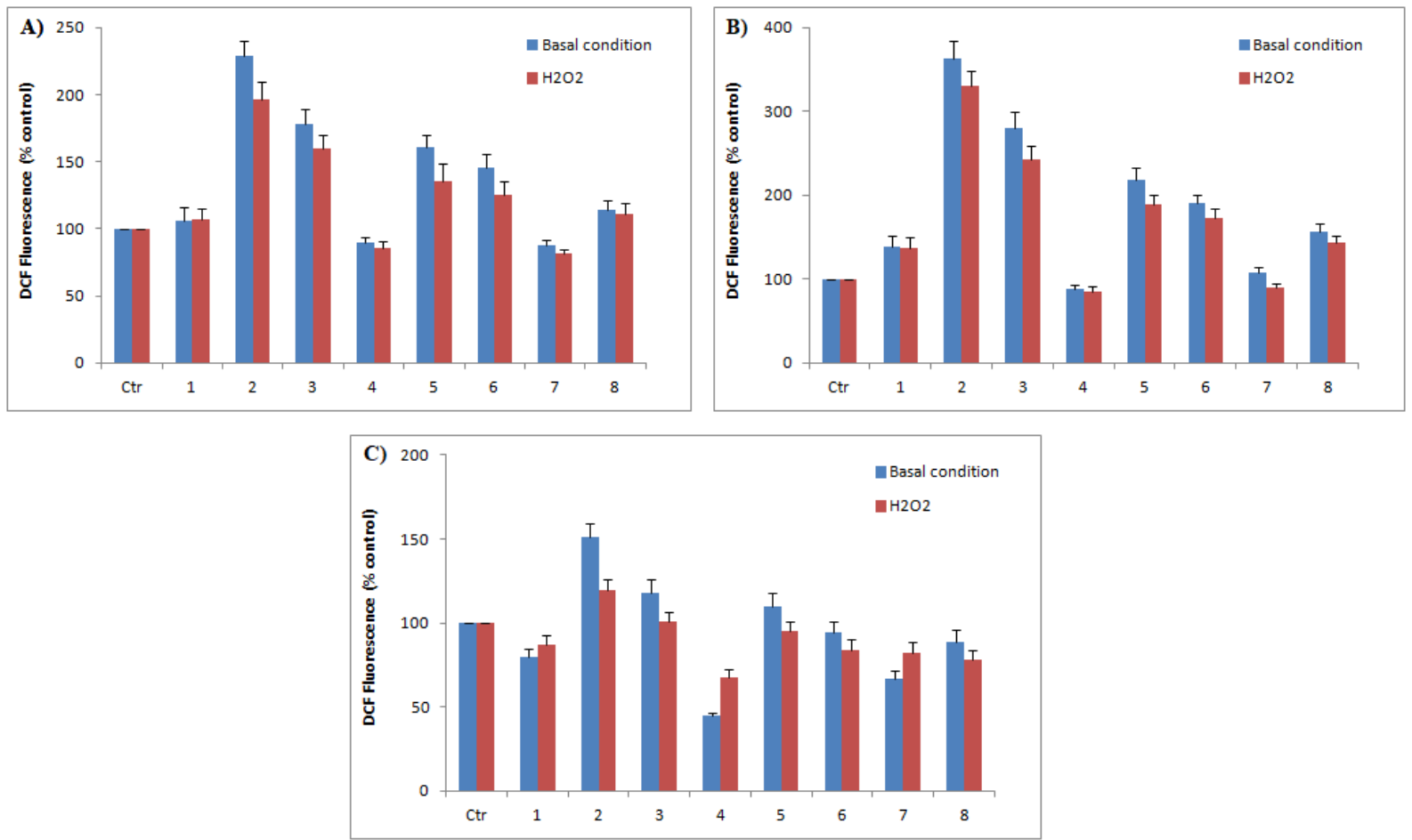

Figure 2. Effects of tested compounds on intracellular ROS production in Rat-1 cells, using DCF (10 $\mathrm{M})$ as the fluorescent probe. DCF fluorescence was measured at basal conditions (blue bars) or following cell exposure to $100 \mu \mathrm{M} \mathrm{H}_{2} \mathrm{O}_{2}$ for $15 \mathrm{~min}$ (red bars) and a 1,16 or $48 \mathrm{~h}(\mathbf{A}, \mathbf{B}$ and $\mathbf{C}$ respectively) pre-treatment with the indicated compounds. The values are expressed as \% compared to the fluorescence value observed in untreated control cells, which was set at 100. Experiments were performed three times on triplicate samples. The SD was $<20 \%$ for all tested conditions.

Interestingly, the compound 4 under basal conditions showed inhibitory activity of at least $60 \%$ after 48 hours. The compound 1 and $\mathbf{2}$ respectively with lupane skeleton and oleane-like triterpene, both with hydroxyl groups at positions C3, C16, C23 and C28 showed a markedly different antioxidant activity. The activity of compound 1 results to be much higher than $\mathbf{2}$. Compound 3 
consists of the corresponding peracetylated of compound $\mathbf{2}$ and showed a higher activity. It is interesting to note that the most active compounds $\mathbf{4}$ and $\mathbf{7}$ are acetylated to hydroxyl groups at positions $\mathrm{C} 3, \mathrm{C} 16, \mathrm{C} 23$ and $\mathrm{C} 28$, and show a 2S-methylbutanoyl unit at hydroxyl group of C-21 carbon. The only difference is due to the presence of an acetyl group at C-22 carbon in the compound 7. In contrast, the compounds $\mathbf{5}$ and $\mathbf{6}$ have the hydroxyl groups not acylated and presented a low antioxidant activity. Moreover, between the compounds $\mathbf{6}$ and $\mathbf{8}$ that differ for the acid unit bound to position C-21, the compound $\mathbf{8}$ appears to be more active.

In conclusion, some of triterpenes isolated by G. sylvestre leaves were able to reduce the basal endogenous levels of ROS, but most importantly, they were also able to prevent an $\mathrm{H}_{2} \mathrm{O}_{2}$-induced generation of intracellular ROS. These findings warrant further studies to better characterize the properties of these compounds and their effects on intracellular ROS, which as shown for well-known antioxidants such as lycopene and $\beta$-carotene, might be affected by the concentration used, as well as several other cellular variables [24-25].

\section{Acknowledgments}

We thank the Associazione Italiana per la Promozione delle Ricerche su Ambiente e Salute umana (AIPRAS-ONLUS) for grants in support of this investigation.

\section{Supporting Information}

Supporting information accompanies this paper on http://www.acgpubs.org/journal/records-ofnatural-products

\section{ORCID}

Valeria Romanucci: 0000-0003-0317-5140

Maria Giordano: 0000-0001-5463-3768

Sergio Davinelli: 0000-0003-2578-7199

Cinzia Di Marino: 0000-0001-5897-2337

Afef Ladhari: 0000-0001-8906-5748

Anna De Marco: 0000-0002-3774-5538

\section{References}

[1] D. Hooper (1887). An examination of the leaves of Gymnema sylvestre, Nature. 35, 565-567.

[2] R. Bansal, R. S. Jat, S. Kumbhani and J. H. Rathod (2016). Ethnomedicinal survey of medicinal plants use from Narmada, Gujarat, India, Med. Plants 8, 233-237.

[3] B. D'Abrosca, M. Della Greca, A. Fiorentino, P. Monaco, A. Natale, P. Oriano and A. Zarrelli (2005). Structural characterization of phytotoxic terpenoids from Cestrum parqui, Phytochemistry 66, 26812688.

[4] M. Della Greca, A. Fiorentino, P. Monaco, L. Previtera and A. Zarrelli (1995). Effusides I-V: 9,10dihydrophenanthrene glucosides from Juncus effusus, Phytochemistry 40, 533-535.

[5] B. D'Abrosca, M. Della Greca, A. Fiorentino, P. Monaco and A. Zarrelli (2004). Low molecular weight phenols rom the bioactive aqueous fraction of Cestrum parqui, J. Agr. Food Chem. 52, 4101-4108.

[6] F. Cutillo, M. DellaGreca, M. Gionti, L. Previtera and A. Zarrelli (2006). Phenols and lignans from Chenopodium album, Phytochem. Anal. 17, 344-349.

[7] M. Della Greca, A. Fiorentino, P. Monaco, L. Previtera and A. Zarrelli (2002). A new dimeric 9,10dihydrophenanthrenoid from the rhizome of Juncus acutus, Tetrahedron Lett. 43, 2573-2575.

[8] M. Della Greca, A. Fiorentino, P. Monaco, L. Previtera, F. Temussi and A. Zarrelli (2003). New dimeric phenanthrenoids from the rhizomes of Juncus acutus. Structure determination and antialgal activity, Tetrahedron 59, 2317-2324.

[9] M. Dellagreca, A. Fiorentino, A. Izzo, F. Napoli, R. Purcaro and A. Zarrelli (2007). Phytotoxicity of secondary metabolites from Aptenia cordifolia, Chem. Biodivers. 4, 118-128. 
[10] A. Fiorentino, M. Della Greca, B. D'Abrosca, P. Oriano, A. Golino, A. Izzo, A. Zarrelli and P. Monaco (2007). Lignans, neolignans and sesquilignans from Cestrum parqui l'Her, Biochem. Syst. Ecol. 35, 392396.

[11] M. Della Greca, M. Isidori, M. Lavorgna, P. Monaco, L. Previtera and A. Zarrelli (2004). Bioactivity of phenanthrenes from Juncus acutus on Selenastrum capricornutum, J. Chem. Ecol. 30, 867-879.

[12] M. DellaGreca, L. Previtera, R. Purcaro and A. Zarrelli (2007). Cinnamic ester derivatives from Oxalis pes-caprae (Bermuda buttercup), J. Nat. Prod. 70, 1664-1667.

[13] T. Cangiano, M. Della Greca, A. Fiorentino, M. Isidori, P. Monaco and A. Zarrelli (2002). Effect of entlabdane diterpenes from potamogetonaceae on Selenastrum capricornutum and other aquatic organisms, J. Chem. Ecol. 28, 1091-1102.

[14] G. Di Fabio, V. Romanucci, C. Di Marino, A. Pisanti and A. Zarrelli (2015). Gymnema sylvestre R. Br., an Indian medicinal herb: traditional uses, chemical composition, and biological activity, Curr. Pharm. Biotechnol. 16, 506-516.

[15] A. Zarrelli, A. Ladhari, R. Haouala, G. Di Fabio, L. Previtera and M. DellaGreca (2013). New acylate oleanane and lupane triterpenes from Gymnema sylvestre, Helv. Chim. Acta 96, 2200-2206.

[16] T. Cangiano, M. DellaGreca, A. Fiorentino, M. Isidori, P. Monaco and A. Zarrelli (2001). Lactone diterpenes from the aquatic plant Potamogeton natans, Phytochemistry 56, 469-473.

[17] A. Pollio, A. Zarrelli, V. Romanucci, C. Di Mauro, F. Barra, G. Pinto, E. Crescenzi, E. Roscetto and G. Palumbo (2016). Polyphenolic profile and targeted bioactivity of methanolic extracts from Mediterranean ethnomedicinal plants on human cancer cell lines, Molecules 21, 1-23.

[18] F. Hadacek and G. Bachmann (2015). Low-molecular-weight metabolite systems chemistry, Front. Environ. Sci. 3, 1-21.

[19] D. J. Newman (2016). Natural products as sources of new drugs from 1981 to 2014, J. Nat. Prod. 79, 629-661.

[20] S. F. Martin (2017). Natural products and their mimics as targets of opportunity for discovery, J. Org. Chem. 82, 10757-10794.

[21] G. Di Fabio, V. Romanucci, C. Di Marino, L. De Napoli and A. Zarrelli (2013). A rapid and simple chromatographic separation of diastereomers of silibinin and their oxidation to produce 2, 3dehydrosilybin enantiomers in an optically pure form, Planta Med. 79, 1077-1080.

[22] F. Prestinaci, P. Pezzotti and A. Pantosti (2015). Antimicrobial resistance: a global multifaceted phenomenon, Pathog. Glob. Health 109, 309-318.

[23] C. D. Beverly and G. Sudarsanam (2013). Antimicrobial activity of Gymnema sylvestre (Asclepiadaceae), J. Acute Dis. 222-225.

[24] S. Yeh and M. J. Hu (2000). Antioxidant and pro-oxidant effects of lycopene in comparison with betacarotene on oxidant-induced damage in Hs68 cells, J. Nutr. Biochem. 11, 548-554.

[25] P. Zhang and S. T. Omaye (2001). Antioxidant and prooxidant roles for $\beta$-carotene, $\alpha$-tocopherol and ascorbic acid in human lung cells, Toxicol. in Vitro 15, 13-24.

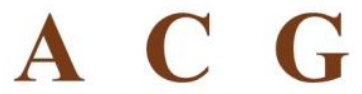

publications

(C) 2020 ACG Publications 